\title{
(6) \\ Breast feeding and intergenerational social mobility: what are the mechanisms?
} OPEN ACCESS

\author{
A Sacker, ${ }^{1}$ Y Kelly, ${ }^{1}$ M lacovou, ${ }^{2}$ N Cable, ${ }^{1}$ M Bartley ${ }^{1}$
}

- Additional material is published online only. To view please visit the journal online (http://dx.doi.org/10.1136/ archdischild-2012-303199).

${ }^{1}$ Research Department of Epidemiology and Public Health, University College London, London, UK ${ }^{2}$ Institute for Social and Economic Research, University of Essex, Colchester, UK

\section{Correspondence to} Professor Amanda Sacker, Research Department of Epidemiology and Public Health, University College London, 1-19 Torrington Place, London WC1E 6BT, UK; a. sacker@ucl.ac.uk

Received 12 October 2012 Revised 25 March 2013 Accepted 25 March 2013 Published Online First 25 June 2013

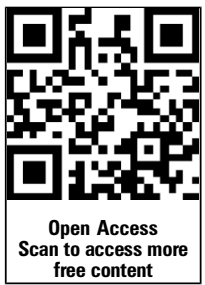

\section{SLinked}

- http://dx.doi.org/10.1136/ archdischild-2013-304188

To cite: Sacker A, Kelly Y, lacovou $\mathrm{M}$, et al. Arch Dis Child 2013;98:666-671.

\section{ABSTRACT}

Objective To investigate the association between breast feeding and intergenerational social mobility and the possible mediating role of neurological and stress mechanisms.

Design Secondary analysis of data from the 1958 and the 1970 British Cohort Studies.

Setting Longitudinal study of individuals born in Britain during 1 week in 1958 and 1970.

Participants 17419 individuals participated in the 1958 cohort and 16771 in the 1970 cohort. The effect of breast feeding on intergenerational social mobility from age 10/11 to age 33/34 was analysed after multiple imputations to fill in missing data and propensity score matching on a wide range of confounders measured in childhood (1958 cohort $\mathrm{N}=16$ 039-16 154; 1970 cohort $\mathrm{N}=16$ 255-16 361). Main outcome measures Own Registrar General's Social Class (RGSC) at 33/34 years adjusted for father's RGSC at 10/11 years, gender and their interaction. Results Breastfed individuals were more likely to be upwardly mobile (1958 cohort: OR $1.2495 \% \mathrm{Cl} 1.12$ to 1.38; 1970 cohort: OR $1.2495 \% \mathrm{Cl} 1.12$ to 1.37$)$ and less likely to be downwardly mobile (1958 cohort: OR $0.8195 \%$ Cl 0.73 to 0.90; 1970 cohort: OR 0.79 95\% $\mathrm{Cl} 0.71$ to 0.88$)$. In an ordinal regression model, markers of neurological development (cognitive test scores) and stress (emotional stress scores) accounted for approximately $36 \%$ of the relationship between breast feeding and social mobility.

Conclusions Breast feeding increased the odds of upward social mobility and decreased the odds of downward mobility. Consistent with a causal explanation, the findings were robust to matching on a large number of observable variables and effect sizes were alike for two cohorts with different social distributions of breast feeding. The effect was mediated in part through neurological and stress mechanisms.

\section{INTRODUCTION}

Breast feeding is known to confer a number of benefits to the developing child. Both the constituents of breast milk and the act of breast feeding have been implicated in the process. Constituents that may offer developmental advantages include long-chain polyunsaturated fatty acids (LCPUFA), immunoglobulins and growth factors. LCPUFAs are essential for neurological development, being needed for metabolic functioning, and dietary intake can boost levels synthesised in the body. Evidence of their benefits for neurological development from trials of LCPUFA added to formula is inconclusive. ${ }^{1}$ Nevertheless, many studies find a positive relationship between breast feeding and cognitive outcomes in childhood ${ }^{2}$ and adulthood ${ }^{3}$ although there are

\section{What is already known on this topic}

Breast feeding confers a number of health and cognitive benefits on the developing child.

- Cognitive and non-cognitive advantages make upward social mobility more likely.

\section{What this study adds}

- Breast feeding increased chances of upward social mobility and decreased chances of downward social mobility.

- The effects were explained in part by the indicator of neurological development, cognitive test scores.

- Consistent with a causal explanation, effect sizes were alike across two cohorts with different social distributions of breast feeding and robust to matching on many confounders.

some exceptions. ${ }^{45}$ There is also evidence linking breast feeding with temperament, ${ }^{6}$ self-regulation ${ }^{7}$ and a lower risk of adjustment problems, ${ }^{8}$ although effects are weaker. Antibodies such as IgA, present in breast milk, are a source of passively acquired immunity for the infant, ${ }^{9}$ while nerve growth factors and insulin-like growth factors support neuronal and general physiological growth and the maintenance of good health. ${ }^{10}$ Observational studies have shown breast feeding to protect children against infections and to promote physical development. ${ }^{11}{ }^{12} \mathrm{~A}$ WHO review queried whether the associations are related to the constituents of breast milk or whether breast feeding enhances the bonding between mother and child. ${ }^{13}$ Maternal skin-to-skin contact during nursing was thought to improve bonding, although this has since been questioned. ${ }^{1415}$ Yet, work with rats showed a greater frequency of licking and grooming during nursing associated with a lower magnitude hypothalamicpituitary-adrenal (HPA) response to acute stress when full-grown, ${ }^{16}$ suggesting skin-to-skin contact could influence development of the infant's stress response through changes in HPA axis functioning. The mechanisms are complex with skin-to-skin contact also influencing maternal stress functioning, in turn affecting the cortisol levels of breast milk. ${ }^{17}$

Cognitive and non-cognitive markers of development predict socioeconomic attainment in adulthood. ${ }^{18-22}$ The UK government strategy on 
intergenerational social mobility aims to ensure that everyone has a fair chance of getting a better job than their parents. ${ }^{23}$ If breast feeding is related to neurological development and stress mechanisms, and cognition and behaviour in childhood are in turn related to occupational destinations in adulthood, then it is pertinent to ask whether breast feeding has any impact on social mobility. To date, the putative causal role for breast feeding in social mobility has been examined in only one study; ${ }^{24}$ this study investigated only upward mobility for a sample of adults born before 1940. The authors found a modest effect of breast feeding on upward social mobility but cautioned against the possibility of residual confounding. Direct comparisons between breastfed and non-breastfed respondents in observational studies may be misleading if breastfed individuals differ systematically from those not breast fed. ${ }^{25}$ Propensity score matching is one method to adjust for selection effects by mimicking some of the characteristics of a randomised controlled trial. ${ }^{26}$ An alternative method was proposed in a recent study which concluded that causal inference in observational studies can be improved by comparing associations for populations with differing confounding structures. ${ }^{27}$

This paper therefore adds to what is known in four important ways: (i) by using data from two more recent British birth cohorts with differing social distributions of breast feeding; (ii) taking a propensity score matching approach to more reliably control for factors predictive of breast feeding and of social destinations; (iii) examining whether breast feeding increases the chances of upward social mobility and protects against downward social mobility; and (iv) exploring the role of neurological development and stress mechanisms in mediating the relationship between breast feeding and social mobility.

\section{METHODS}

The 1958 cohort comprises 17419 individuals born during 1 week in 1958 in Britain. ${ }^{28}$ The cohort was followed at ages 7, $11,16,23,33,42,46$ and 50, with face-to-face interviews with parents, teachers and cohort members; educational assessments; and medical examinations. We use data from birth (response 98.8\%) to age 33 (response 70.2\%). The British 1970 cohort consists of 16771 children also born in 1 week of that year. ${ }^{29}$ The cohort was similarly followed up when the members were aged $5,10,16,26,30,34,38$ and 42 years, although the 42-year follow-up has not been released at the time of writing. Data from birth (response 95.9\%) to age 34 (response 73.7\%) were used.

\section{Main study variables}

Mothers were asked when their child was age 7 (1958 cohort) or age 5 (1970 cohort) whether they had breast fed their child. Responses indicate whether the child had never been breast fed, breast fed for less than 4 weeks or breast fed for 4 weeks or more. Parental recall of breast feeding practices after many years has been shown to be reliable and valid. ${ }^{30} 31$

Father's social class when aged 11 (1958 cohort) or age 10 (1970 cohort) and own social class at age 33 (1958 cohort) or 34 (1970 cohort) were measured using the Registrar General's social class. ${ }^{32}$ The original six-category schema was reduced to four by combining the top two and bottom two categories, providing larger numbers in the extreme groups. Reordered scales ranged from class IV and $\mathrm{V}$ (unskilled/semiskilled manual) to class I and II (professional/managerial). Gender was coded with male as the reference category. Mediating variables were assessed at age 11 (1958 cohort) or 10 (1970 cohort).

Neurological ability was measured by cognitive test scores administered at 11 years (1958 cohort) or 10 years (1970 cohort). Cognition was assessed in the 1958 cohort by the National Foundation for Educational Research (NFER) General Ability Test, ${ }^{33}$ administered at school. Two verbal (Word Definitions; Word Similarities) and two non-verbal subscales (Recall of Digits; Matrices) of the British Ability Scales were administered by the 1970 cohort members' teachers. ${ }^{34}$ Emotional stress scores were assessed by mothers and teachers, also at 10/11 years. For the 1958 cohort, the former completed the Rutter A scale and the latter the Bristol Social Adjustment Guide. ${ }^{35}$ Mothers of the 1970 cohort members completed the Rutter A scale and teachers the Rutter B scale. ${ }^{36} 37$ All mediators were categorised into quintiles to facilitate comparison between the cohorts and allow for non-linear relationships with social mobility.

\section{Statistical analysis}

Some variables had missing values. Multiple imputations were used to create 20 filled-in datasets for each cohort (see online supplementary appendix A for details). Three cases each from the 1958 and 1970 cohorts were excluded because of missing or inconsistent data on gender and three cases were excluded from the 1958 cohort because region of birth was missing since it was not felt that these variables could be imputed beyond chance levels (effective sample $\mathrm{N}=17413$ (1958 cohort); 16768 (1970 cohort)). To control for selection bias influencing who was breast fed, we carried out propensity score matching. ${ }^{25}$ An estimate of the propensity score was obtained by probit regression of a binary treatment indicator (any breast feeding vs none) on baseline covariates (details in online supplementary appendix B). Propensity scores for each respondent in the filled-in datasets were estimated. Postmatching, sample sizes ranged from 16039 to 16154 for the 1958 cohort and 16255 to 16361 for the 1970 cohort. Substantive models were estimated on the matched samples with coefficients averaged and SEs adjusted according to Rubin's rules. ${ }^{38}$

Upward mobility was defined as having a higher social class at age 33/34 than father's social class at 10/11 years. Downward mobility was defined similarly as the respondent having a lower class than their father. For upward mobility, respondents whose fathers were in the top category were excluded as they could not move upwards (1958 cohort: mean $\mathrm{N}=4325$; 1970 cohort: mean $\mathrm{N}=4819$ ) before comparing the upwardly mobile with those who were not (the downwardly mobile or stable). Logistic regression examined the influence of breast feeding on upward social mobility using gender, social class in childhood and a gender by social class interaction as additional covariates since women's social mobility patterns differ from men's. ${ }^{39}$ Similarly, the odds of downward social mobility if breast fed were estimated after excluding cohort members whose fathers were in the lowest social class group (1958 cohort: mean $\mathrm{N}=4476$; 1970 cohort: mean $\mathrm{N}=2912$ ).

Since absolute values of the odds of upward and downward mobility were equal in both cohorts (see Results section and table 1), ordinal logistic regression was used to examine the role of the putative mediators. For Model 1, the dependent variable was own social class at age 33/34 conditional on breast feeding, gender, father's social class and the gender by father's class interaction, essentially replicating the earlier models. In Model 2, the indicator of neurological development (cognitive test scores) was added whereas in Model 3, the emotional stress scores were added. Model 4 included both neurological and stress variables. Breast feeding ORs are interpreted as the odds of being one category higher in the social hierarchy, given childhood social class and values on other covariates. 
Table 1 ORs and 95\% Cls from multivariable logistic regression models of upward and downward social mobility in the 1958 and 1970 cohorts

\begin{tabular}{|c|c|c|c|c|}
\hline & \multicolumn{2}{|l|}{1958 cohort } & \multicolumn{2}{|l|}{1970 cohort } \\
\hline & OR & $95 \% \mathrm{Cl}$ & OR & $95 \% \mathrm{Cl}$ \\
\hline \multicolumn{5}{|l|}{ Upward mobility } \\
\hline Breast fed & 1.24 & 1.12 to 1.38 & 1.24 & 1.12 to 1.37 \\
\hline Female & 0.65 & 0.50 to 0.84 & 0.80 & 0.62 to 1.03 \\
\hline \multicolumn{5}{|l|}{ RGSC in childhood* } \\
\hline $\mid / I I$ & (excluded)† & & (excluded) $†$ & \\
\hline IIINM & 1.00 & & 1.00 & \\
\hline IIIM & 1.04 & 0.85 to 1.28 & 1.06 & 0.88 to 1.27 \\
\hline IV/V & 2.84 & 2.29 to 3.54 & 3.26 & 2.56 to 4.11 \\
\hline \multicolumn{5}{|c|}{ Gender by RGSC interaction } \\
\hline Female* $\mathrm{I} / \mathrm{II}$ & (excluded) $\dagger$ & & (excluded) $\dagger$ & \\
\hline Female* IIINM & 1.00 & & 1.00 & \\
\hline Female* IIIM & 2.53 & 1.92 to 3.34 & 1.98 & 1.52 to 2.58 \\
\hline Female* IV/V & 1.15 & 0.85 to 1.56 & 1.03 & 0.71 to 1.49 \\
\hline$N \ddagger$ & \multicolumn{2}{|l|}{$12429-12548$} & \multicolumn{2}{|l|}{$11773-11900$} \\
\hline \multicolumn{5}{|l|}{ Downward mobility } \\
\hline Breast fed & 0.81 & 0.73 to 0.90 & 0.79 & 0.71 to 0.88 \\
\hline Female & 1.40 & 1.22 to 1.60 & 1.13 & 0.95 to 1.33 \\
\hline \multicolumn{5}{|c|}{ RGSC in childhood§ } \\
\hline $\mid / I I$ & 2.49 & 2.13 to 2.93 & 2.99 & 2.54 to 3.54 \\
\hline IIINM & 2.08 & 1.66 to 2.60 & 2.26 & 1.79 to 2.85 \\
\hline IIIM & 1.00 & & 1.00 & \\
\hline IV/V & (excluded)१ & & (excluded)ף & \\
\hline \multicolumn{5}{|c|}{ Gender by RGSC interaction } \\
\hline Female* $^{*} / \mathrm{II}$ & 1.12 & 0.92 to 1.37 & 1.09 & 0.88 to 1.35 \\
\hline Female* IIINM & 0.54 & 0.40 to 0.73 & 0.64 & 0.47 to 0.89 \\
\hline Female* IIIM & 1.00 & & 1.00 & \\
\hline Female* IV/V & (excluded)ף & & (excluded)ף & \\
\hline $\mathrm{N} \ddagger$ & $12152-12276$ & & 13 311-13 482 & \\
\hline
\end{tabular}

*Registrar General's social class (RGSC) when child aged 11.

tCases excluded because upward social mobility is logically impossible for this category.

$\ddagger$ Sample sizes for the 20 filled-in datasets after propensity score matching has been applied and logically impossible cases excluded.

§RGSC when child aged 10.

TCases excluded because downward social mobility is logically impossible for this category. IIINM, III non-manual; IIIM, III manual.

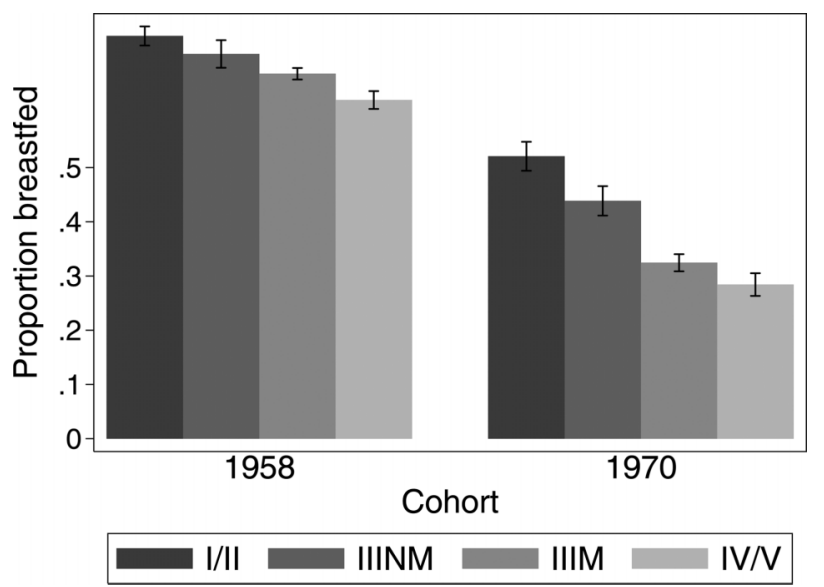

Figure 1 Proportion of children in the 1958 and 1970 cohorts who were breast fed by father's social class at birth (data averaged over 20 filled-in datasets). IIINM, III non-manual; IIIM, III manual.
To compare how breast feeding was socially distributed in the two cohorts, we estimated the Relative Index of Inequality (RII). ${ }^{40}$ Larger RII imply larger breastfeeding differences between professional/managerial and non-skilled social classes. The magnitude of the RII can be attributed to the effect of social class on breast feeding and to inequalities in the distribution of social class itself. Post hoc tests to compare model coefficients between cohorts were carried out using the Stata suest (seemingly unrelated estimation) command.

\section{RESULTS}

In the 1958 cohort, $68 \%$ of mothers breast fed their children compared with $36 \%$ in the 1970 cohort. Figure 1 highlights that breast feeding was significantly more socially distributed in the 1970 cohort than the 1958 cohort (RII 1958 cohort 1.94, 95\% CI 1.69 to 2.22 ; RII 1970 cohort 3.62 , 95\% CI 3.15 to 4.16). The pattern of social mobility also differed between the two cohorts (table 2). Upward social mobility was more likely in the 1970 than the 1958 cohort, but at the same time downward social mobility was less likely in the later born cohort. Total mobility, similar in both cohorts, thus masks differences in upward and downward movements.

Individuals who had been breast fed were more likely to move up the social hierarchy (table 1). The chances of upward mobility were the same for the 1958 cohort (OR 1.24; 95\% CI 1.12 to 1.38 ) and the 1970 cohort (OR $1.24 ; 95 \%$ CI 1.12 to 1.37). Downward social mobility was also related to breastfeeding status: breastfed cohort members were less likely to move down, with ORs of 0.81 and 0.79 for the 1958 and 1970 cohorts, respectively. Post hoc tests confirmed that effects were equivalent in magnitude across cohorts and for upward and downward mobility.

The mediators were all related to breast feeding and to social mobility in both cohorts (table 3) with the exception of the maternal reported emotional stress score which had inconsistent associations by cohort. Nevertheless, for completeness, the score was included in the mediation models reported in table 4 . Excluding this variable did not alter the findings substantively.

In table 4 , Model 1 is a respecification of the upward and downward models that assumes the effects of breast feeding on upward and downward social mobility are equal in magnitude and opposite in direction, as confirmed by the post hoc tests. Model 2 shows that there is some attenuation of the estimate for breast feeding after controlling for cognitive test scores suggesting that the effect of breast feeding effect may operate through neurological development. The role for stress mechanisms is more tenuous with very little attenuation by the emotional and physical stress scores (Model 3). Finally in Model 4, all the proposed mediators are entered simultaneously, confirming that breast feeding is mainly mediated via neurological development. Approximately 36\% of the effect of breast feeding is accounted for by the mediators.

\section{DISCUSSION}

This is the first large population-based study to investigate the relationship between, and potential mechanisms underlying, breast feeding and intergenerational social mobility. We employed two analytic strategies to strengthen a causal interpretation: propensity score matching and the comparison of associations between cohorts with differing distributions of breast feeding by social class. ${ }^{25} 27$ The results show that breast feeding was consistently associated with an increased chance of upward social mobility and a decreased chance of downward mobility. The same effect size was observed in two cohorts born 12 years 
Table 2 Intergenerational social mobility* in the 1958 and 1970 cohort studies

\begin{tabular}{|c|c|c|c|c|}
\hline \multirow{2}{*}{ Social class in childhood } & \multirow[b]{2}{*}{$\mathrm{N}$} & \multicolumn{3}{|c|}{ Social mobility into adulthood } \\
\hline & & Upward & Stable & Downward \\
\hline \multicolumn{5}{|l|}{1958 cohort } \\
\hline I/II & 3876 (3764 to 3989$)$ & NA & 0.55 (0.53 to 0.57 ) & 0.45 (0.43 to 0.47$)$ \\
\hline IIINM & 1576 (1488 to 1665$)$ & 0.41 (0.38 to 0.44 ) & $0.26(0.24$ to 0.29$)$ & $0.32(0.30$ to 0.35$)$ \\
\hline IIIM & 7306 (7163 to 7448$)$ & 0.52 (0.51 to 0.54$)$ & $0.23(0.22$ to 0.24$)$ & $0.24(0.23$ to 0.26$)$ \\
\hline IV/V & 4010 (3892 to 4127 ) & 0.67 (0.65 to 0.69$)$ & 0.33 (0.31 to 0.35$)$ & NA \\
\hline $\mathrm{N}$ & & 7160 (7005 to 7314$)$ & 5559 (5417 to 5701$)$ & 4050 (3925 to 4174$)$ \\
\hline \multicolumn{5}{|l|}{1970 cohort } \\
\hline I/II & 4819 (4688 to 4950$)$ & NA & 0.60 (0.58 to 0.62$)$ & 0.40 (0.38 to 0.42$)$ \\
\hline IIINM & 1497 (1414 to 1581) & 0.48 (0.45 to 0.51$)$ & $0.23(0.20$ to 0.25$)$ & 0.29 (0.26 to 0.32$)$ \\
\hline IIIM & 7540 (7381 to 7698$)$ & 0.57 (0.56 to 0.58$)$ & $0.24(0.23$ to 0.25$)$ & $0.19(0.17$ to 0.20$)$ \\
\hline $\mathrm{IV} / \mathrm{V}$ & 2912 (2793 to 3031) & 0.75 (0.72 to 0.77 ) & $0.25(0.22$ to 0.28$)$ & NA \\
\hline $\mathrm{N}$ & & 7192 (7033 to 7351$)$ & 5785 (5619 to 5952 ) & 3790 (3647 to 3934 ) \\
\hline
\end{tabular}

*Proportion mobile based on Registrar General's social class of father at age 11 (1958 cohort) or age 10 (1970 cohort) and own Registrar General's social class at age 33 (1958 cohort)

or age 34 (1970 cohort). Data averaged over 20 filled-in datasets with sample size 17413 (1958 cohort) and 16768 (1970 cohort). IIINM, III non-manual; IIIM, III manual.

apart who had different social patterning of breast feeding and different patterns of intergenerational social class mobility.

Mediation models suggested that breast feeding advanced neurological development resulting in improved cognitive performance which in turn supported upward social mobility and protected against downward social mobility. Children who seemed to be under greater stress were less likely to be upwardly mobile and more likely to be downwardly mobile, and breastfed children showed fewer signs of emotional stress. However, this pathway was less important than the neurological one.

A major strength of the study is that the data are representative of the British population. Large-sample representative longitudinal data from birth to mid-adulthood are rare outside the UK. Since both cohorts had their origins in studies of perinatal mortality, data collection included a broad range of information on the circumstances surrounding birth and allowing inclusion of a large number of potential confounding factors known to affect breastfeeding initiation and maintenance in the propensity score models. Matching of breastfed and formula fed children attenuated the breastfeeding effect compared with standard ordinary least squares (OLS) estimates (data not shown), consistent with assumptions that confounding could bias results. While one can never rule out the possibility that residual confounding is still present, the consistency of our results across cohorts lends support to a causal mechanism. The study also benefited from the regular interviewing of cohort members and their families, allowing for the missing at random assumption of the imputation models to be supported using auxiliary variables from other data collection sweeps, although we cannot exclude the possibility that data were missing not at random.

A limitation is that breast feeding was measured retrospectively according to maternal report. This may result in some misclassification. It was also not possible to derive a more fine-grained measure of breastfeeding duration together with the propensity score matching approach. Supplementary analyses (not shown) indicated that effect sizes were larger if children breast fed for less than 4 weeks were compared with children breast fed for 4 or more weeks and greater still if children who were not breast fed were compared with those breast fed for 4 or more weeks, suggesting a dose-response effect or possibly a reduction in effect size due to misclassification. A further limitation is the lack of clinical measures, relying on maternal and teacher reports of emotional stress which could be prone to response bias. However, using multi-informant reports can counteract this problem. ${ }^{41}$ Finally, while the formal comparison of the RIIs measuring social class differences in breast feeding in each of the two cohorts confirmed a statistically significant difference, this was not as dramatic a contrast as in the Brion et al paper. ${ }^{27}$

To our knowledge, only one study has directly assessed the effect of breast feeding on upward social mobility. ${ }^{24}$ In that study, only $44 \%$ of eligible respondents had data on social class in both childhood and adulthood and on breast feeding in

Table 3 Mean scores* with $95 \%$ Cls in parentheses for the childhood mediators by breastfeeding status

\begin{tabular}{|c|c|c|c|c|}
\hline & \multicolumn{2}{|l|}{1958 cohort } & \multicolumn{2}{|l|}{1970 cohort } \\
\hline & Not breast fed & Breast fed & Not breast fed & Breast fed \\
\hline Cognitive test scoret & 98.06 (97.63 to 98.49$)$ & 101.13 (100.83 to 101.42$)$ & 98.36 (98.05 to 98.67$)$ & 102.11 (101.64 to 102.57$)$ \\
\hline Maternal reported emotional stress score $\ddagger$ & $-0.013(-0.043$ to 0.018$)$ & $0.002(-0.020$ to 0.023$)$ & 0.026 (0.006 to 0.045$)$ & $-0.030(-0.059$ to -0.001$)$ \\
\hline \multirow[t]{2}{*}{ Teacher reported emotional stress scoreł } & 0.058 (0.028 to 0.088$)$ & $-0.039(-0.059$ to -0.020$)$ & 0.034 (0.013 to 0.055$)$ & $-0.048(-0.079$ to -0.017$)$ \\
\hline & Upwardly mobile & Downwardly mobile & Upwardly mobile & Downwardly mobile \\
\hline Cognitive test scoret & $101.26(99.80$ to 100.71$)$ & 97.43 (96.83 to 98.02 ) & 99.78 (99.39 to 100.17$)$ & 96.74 (96.16 to 97.33$)$ \\
\hline Maternal reported emotional stress scoreł & $-0.048(-0.075$ to -0.021$)$ & $0.066(0.029$ to 0.104$)$ & 0.032 (0.004 to 0.060$)$ & $0.032(-0.007$ to 0.071$)$ \\
\hline Teacher reported emotional stress scoreł & $-0.116(-0.142$ to -0.091$)$ & $0.141(0.101$ to 0.180$)$ & $-0.028(-0.063$ to 0.006$)$ & $0.126(0.076$ to 0.176$)$ \\
\hline
\end{tabular}

*Data averaged over 20 filled-in datasets after propensity score matching has been applied with sample sizes $16039-16154$ (1958 cohort) and $16255-16361$ (1970 cohort).

tScores standardised to have mean 100, SD 15.

¥Scores standardised to have mean 0 , SD 1. 
infancy $(\mathrm{N} \approx 1400)$. The authors acknowledged that they were neither able to investigate causal pathways nor to rule out the possibility of residual confounding. Interestingly though, their estimates of the causal effect of breast feeding were very similar to ours. Studies that have estimated effects separately for low birth weight and preterm infants have tended to show that shorter term benefits are greater for these children than healthy full-term children. ${ }^{2} 42$ We speculate that the long-term gains from breast feeding for these more vulnerable children may be greater too.

It is difficult to disentangle the independent role for the nutrient content of breast milk versus the role of skin-to-skin contact. While our results show a stronger mediating pathway through neurological development than through stress response mechanisms, studies of supplementation of formula milk suggest that LCPUFAs alone may not improve cognitive development. ${ }^{1} 4344$ However, other bioactive constituents of breast milk may also be important. Skin-to-skin contact has been related to improved mother-child bonding and cognitive functioning. ${ }^{45} 46$ Perhaps the combination of physical contact and the most appropriate nutrients required for growth and brain development is implicated in the better neurocognitive and adult outcomes of breastfed infants. ${ }^{47}$ This might suggest that mothers who do not breast feed could aid their child's development by mimicking the close skin-to-skin contact that breastfeeding mothers naturally have with their infant during feeding and selecting brands of formula that contain LCPUFA. The UNICEF Baby Friendly Initiative aims to increase breastfeeding initiation rates throughout the world. The 2010 Infant Feeding Survey showed that in the UK, only a third of mothers who start to breast feed still do so exclusively at 6 weeks implying that extending the initiative to policies that sustain breast feeding is also recommended.

More research is needed on the association between breast feeding and child cognitive and socio-emotional development if we are to elucidate the causal mechanisms through which breast feeding can have lifelong implications for health and well-being. Identifying subgroups that might benefit most from breast feeding would enable interventions to be targeted more effectively. This necessitates large studies collecting detailed infant feeding data, including duration of partial and exclusive breast feeding, breastfeeding schedules, mode of receiving breast milk, and type of formula together with parental cognitive tests.

Table 4 Relationship of breast feeding with social class in adulthood (ORs and $95 \% \mathrm{Cls}$ ) from ordinal regression social mobility models

\begin{tabular}{|c|c|c|c|c|}
\hline & \multicolumn{2}{|c|}{1958 cohort } & \multicolumn{2}{|c|}{1970 cohort } \\
\hline & OR & $95 \% \mathrm{Cl}$ & OR & $95 \% \mathrm{Cl}$ \\
\hline Model ${ }^{*}$ & 1.24 & 1.13 to 1.36 & 1.29 & 1.19 to 1.40 \\
\hline Model $2 \dagger$ & 1.14 & 1.04 to 1.25 & 1.19 & 1.09 to 1.29 \\
\hline Model 3‡ & 1.22 & 1.12 to 1.33 & 1.28 & 1.18 to 1.38 \\
\hline Model $4 \S$ & 1.14 & 1.04 to 1.25 & 1.19 & 1.09 to 1.29 \\
\hline Nף & \multicolumn{2}{|c|}{16 039-16 154} & \multicolumn{2}{|c|}{$16255-16361$} \\
\hline \multicolumn{5}{|c|}{$\begin{array}{l}{ }^{*} \text { Controlling for gender, social class of father and their interaction. } \\
\text { †Model } 1 \text { plus cognitive test score quintiles. } \\
\text { ‡Model } 1 \text { plus emotional stress score quintiles (mother and teacher reported). } \\
\text { §Model } 1 \text { plus cognitive test score quintiles and emotional stress score quintiles } \\
\text { (mother and teacher reported). } \\
\text { १Sample sizes for the } 20 \text { filled-in datasets after propensity score matching applied to } \\
\text { each dataset. }\end{array}$} \\
\hline
\end{tabular}

In conclusion, our study adds to evidence on the health benefits of breast feeding by showing that there may be lifelong social benefits. Applying propensity score matching and comparing across cohorts with different social distributions of breast feeding goes some way towards overcoming the limitations of observational data, giving us more confidence in a causal interpretation of the findings.

Acknowledgements The authors would like to thank the cohort members and families for their cooperation in the studies and the study teams at the Institute of Education. The UK Economic and Social Research Council funded the 1958 National Child Development Study (study director Jane Elliot) and the 1970 British Cohort

Study (director Alice Sullivan). The cohort data are deposited in the UK Data Archive. Neither the study teams nor the Data Archive bear any responsibility for the analysis or interpretation of the data.

Contributors All authors contributed to the design of the study. NC extracted and cleaned the data. AS and MI performed the data analysis. All authors interpreted the results. AS drafted the paper. MB, MI and YK reviewed and edited the paper. $A S$ is the guarantor. All authors had full access to all of the data (including statistical reports and tables) in the study and take responsibility for the integrity of the data and the accuracy of the data analysis. All authors conducted this work independently of the funders of the cohort studies

Funding This research was supported by the UK Economic and Social Research Council (ESRC): the International Centre for Life course Studies in Society and Health (ICLS) (award no. RES-596-28-0001) and the Research Centre on Micro-Social Change (MiSoC) (award no. RES-518-28-001)

Competing interests All authors have completed the Unified Competing Interests form at http://www.icmje.org/coi_disclosure.pdf (available on request from the corresponding author) and declare: no support from any organisation for the submitted work; no financial relationships with any organisations that might have an interest in the submitted work in the previous 3 years; no other relationships or activities that could appear to have influenced the submitted work.

Ethics approval The 1958 and 1970 birth cohort studies were approved by the London Multicentre Research Ethics Committee.

Provenance and peer review Not commissioned; externally peer reviewed.

Data sharing statement The datasets are available from the UK Data Archive. Further information about the studies and data can be found online (http://www.cls. ioe.ac.uk/).

Open Access This is an Open Access article distributed in accordance with the Creative Commons Attribution Non Commercial (CC BY-NC 3.0) license, which permits others to distribute, remix, adapt, build upon this work non-commercially, and license their derivative works on different terms, provided the original work is properly cited and the use is non-commercial. See: http://creativecommons.org/ licenses/by-nc/3.0/

\section{REFERENCES}

1 Delgado-Noguera MF, Calvache JA, Bonfill Cosp X. Supplementation with long chain polyunsaturated fatty acids (LCPUFA) to breastfeeding mothers for improving child growth and development. Cochrane Database Syst Rev (Online) 2010;(12): CD007901.

2 Anderson JW, Johnstone BM, Remley DT. Breast-feeding and cognitive development: a meta-analysis. Am J Clin Nutr 1999;70:525-35.

3 Mortensen E, Michaelsen K, Sanders SA, et al. The association between duration of breastfeeding and adult intelligence. JAMA2002;287:2365-71.

4 Der G, Batty GD, Deary IJ. Effect of breast feeding on. intelligence in children: prospective study, sibling pairs analysis, and meta-analysis. BMJ 2006;333: 945-48.

5 Gale CR, Martyn CN. Breastfeeding, dummy use, and adult intelligence. Lancet 1996;347:1072-75.

6 Liu F, Ma L-J, Yi M-J. Association of breastfeeding with behavioral problems and temperament development in children aged $4-5$ years. Chin J Contemp Pediatr 2006;8:334-7.

7 Vohr BR, Poindexter BB, Dusick AM, et al. Persistent beneficial effects of breast milk ingested in the neonatal intensive care unit on outcomes of extremely low birth weight infants at 30 months of age. Pediatrics 2007;120:e953-9.

8 Heikkilä K, Sacker A, Kelly Y, et al. Breast feeding and child behaviour in the millennium cohort study. Arch Dis Child 2011;96:635-42

9 Stoliar OA, Pelley RP, Klaus MH, et al. Secretory IgA against enterotoxins in breast milk. Lancet 1976;307:1258-61.

10 Gunnell D, Miller LL, Rogers I, et al. Association of insulin-like growth factor I and insulin-like growth factor-binding protein-3 with intelligence quotient among 8- to 9 -Year-old children in the Avon longitudinal study of parents and children. Pediatrics 2005:116:E681-6. 
11 Quigley M, Kelly Y, Sacker A. Breastfeeding and hospitalization for diarrheal and respiratory infection in the UK Millennium Cohort Study. Pediatrics 2007;119: e837-42.

12 Sacker A, Quigley M, Kelly Y. Breastfeeding and developmental delay: findings from the Millennium Cohort Study. Pediatrics 2006;118:e682-9.

13 Horta BL, Bahl R, Martinés JC, et al. Evidence on the long-term effects of breastfeeding: Systematic review and meta-analyses. Geneva: World Health Organisation, 2007.

14 Lamb ME. Early contact and Maternal-Infant bonding: One decade later. Pediatrics 1982;70:763-8.

15 Eyer D. Mother-infant bonding. Hum Nat 1994;5:69-94.

16 Liu D, Diorio J, Tannenbaum B, et al. Maternal care, hippocampal glucocorticoid receptors, and Hypothalamic-Pituitary-Adrenal responses to stress. Science 1997;277:1659-62.

17 Handlin L, Jonas W, Petersson M, et al. Effects of sucking and Skin-to-Skin contact on maternal ACTH and cortisol levels during the second day Postpartum-Influence of epidural analgesia and oxytocin in the perinatal period. Breastfeed Med 2009:4:207-20.

18 Deary IJ, Taylor MD, Hart CL, et al. Intergenerational social mobility and mid-life status attainment: Influences of childhood intelligence, childhood social factors, and education. Intelligence 2005;33:455-72.

19 Farkas G. Cognitive skills and noncognitive traits and behaviors in stratification processes. Palo Alto, CA: Annual Reviews, 2003.

20 Forrest LF, Hodgson S, Parker L, et al. The influence of childhood IQ and education on social mobility in the Newcastle Thousand Families birth cohort. BMC Public Health 2011;11:895.

21 Freese J. The just meritocracy: IQ, class mobility, and American social policy. Contemp Sociol I Rev 2006;35:250-2.

22 Heckman JJ, Stixrud J, Urzua S. The effects of cognitive and noncognitive abilities on labor market outcomes and social behavior. Cambridge, MA: National Bureau of Economic Research, 2006.

23 HM Government. Opening doors, breaking barriers: a strategy for social mobility. London: Cabinet Office, 2011.

24 Martin RM, Goodhall S, Gunnell DJ, et al. Breastfeeding in infancy and social mobility: 60 year follow-up of the Boyd Orr cohort. Arch Dis Child 2007;92:317-21.

25 Rosenbaum PR, Rubin DB. The central role of the propensity score in observational studies for causal effects. Biometrika 1983;70:41-55.

26 Austin PC. Balance diagnostics for comparing the distribution of baseline covariates between treatment groups in propensity-score matched samples. Stat Med 2009;28:3083-107.

27 Brion M-JA, Lawlor DA, Matijasevich A, et al. What are the causal effects of breastfeeding on IQ, obesity and blood pressure? Evidence from comparing high-income with middle-income cohorts. Int J Epidemiol 2011:40:670-80.

28 Power C, Elliott J. Cohort profile: 1958 British birth cohort (National Child Development Study). Int J Epidemiol 2006:35:34-41.

29 Elliott J, Shepherd P. Cohort Profile: 1970 British Birth Cohort (BCS70). Int J Epidemiol 2006:35:836-43.
30 Tienboon P, Rutishauser I, Wahlqvist M. Maternal recall of infant feeding practices after an interval of 14 to 15 years. Aust J Nutr Diet 1994;51:25-7.

31 Li R, Scanlon KS, Serdula MK. The validity and reliability of maternal recall of breastfeeding practice. Nutr Rev 2005;63:103-10.

32 Leete R, Fox J. Registrar General's social classes: origins and users. Popul Trends 1977;8:1-7.

33 Douglas JWB. The home and the School. London: Macgibbon and Kee, 1964.

34 Elliott C, Murray D, Pearson L. British ability scales. Windsor: National Foundation for Educational Research, 1978.

35 Stott DH. The social adjustment of children. 3rd edn. London: University of London Press, 1964.

36 Rutter M, Tizard J, Whitmore K. Education, health and behaviour. London: Longmans, 1970.

37 McGee R, Williams S, Bradshaw J, et al. The Rutter scale for completion by teachers: factor structure and relationships with cognitive abilities and family adversity for a sample of New Zealand children. I Child Psychol Psychiatry 1985;26:727-39.

38 Rubin DB. Multiple imputation for nonresponse in surveys. New York: John Wiley, 1987.

39 Blanden J, Goodman A, Gregg P, et al. Changes in intergenerational mobility in Britain. London, UK: Centre for the Economics of Education, London School of Economics and Political Science, 2002.

40 Mackenbach JP, Kunst AE. Measuring the magnitude of socio-economic inequalities in health: An overview of available measures illustrated with two examples from Europe. Soc Sci Med 1997;44:757-71.

41 Kolko DJ, Kazdin AE. Emotional/Behavioral problems in clinic and nonclinic children: correspondence among child, parent and teacher reports. I Child Psychol Psychiatry 1993;34:991-1006

42 Quigley MA, Hockley C, Carson C, et al. Breastfeeding is associated with improved child cognitive development: a population-based Cohort Study. J Pediatr 2012;160:25-32

43 Bakker EC, Ghys AJA, Kester ADM, et al. Long-chain polyunsaturated fatty acids at birth and cognitive function at 7 years of age. Eur J Clin Nutr 2003:57:89-95.

44 Eilander A, Hundscheid DC, Osendarp SJ, et al. Effects of n-3 long chain polyunsaturated fatty acid supplementation on visual and cognitive development throughout childhood: a review of human studies. Prostaglandins Leukot Essent Fatty Acids 2007;76:189-203.

45 Christensson K, Siles C, Moreno L, et al. Temperature, metabolic adaptation and crying in healthy full-term newborns cared for skin-to-skin or in a cot. Acta Pædiatrica 1992:81:488-93.

46 Feldman R. Mother-Infant Skin-to-Skin Contact (Kangaroo Care): Theoretical, Clinical, and Empirical Aspects. Infants Young Child 2004;17:145-61.

47 Raju TNK. Breastfeeding is a dynamic biological process-not simply a meal at the breast breastfeeding medicine. Breastfeeding Medicine 2011:6:257-59. 